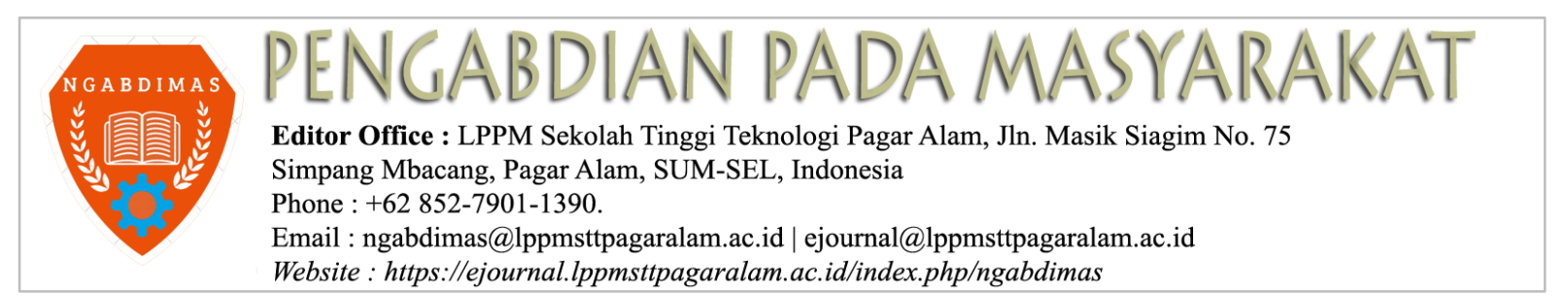

\title{
Pelatihan Pembuatan Aplikasi Pengolahan Nilai Dengan MS. Excel Bagi Guru Sma Negeri 2 Pagar Alam
}

\author{
Desi Puspita \\ Program Studi Teknik Informatika; Sekolah Tinggi Teknologi Pagaralam (STTP) \\ Jl. M. Siagim No.75 Kel. Karang Dalo, Dempo Tengah, Kota Pagar Alam \\ Telp/Fax: (0730) 621916 \\ e-mail: desiofira1@gmail.com.
}

\begin{abstract}
Abstrak
Pengolahan nilai siswa SMAN 2 Kota Pagaralam saat ini dilakukan dengan cara manual, seluruh data dihitung tiap komponen disatukan dan dijumlah menjadi satu diambil rata-rata nantinya didapatkan nilai akhir. Permasalahan ini menjadi titik kelemahan karena guru pelajaran menjadi lambat mengumpulkan nilai siswa. Sehingga pimpinan SMAN 2 Pagaralam berusaha meminimalisir dan meminta civitas (dosen) STTP untuk mengadakan pelatihan pengolahan data nilai menggunakan excel, dengan semangat berbagi ini maka melalui LPPM STTP mengadakan pengabdian pelatihan pengolahan nilai. Pelatihan dilakukan dengan metode penjelasan dan praktek langsung dengan excel, diawali dengan penyiapan data yang diolah dilanjutkan dengan penjelasan dan contoh menggunakan aplikasi dengan excel, agar pelatihan berjalan dengan baik maka dilakukan terlebih dahulu tes pendahuluan untuk mengetahui pemahaman peserta pelatihan terhadap teknik pengolahan data menggunakan excel dan hasilnya mereka rata-rata belum baik dalam pemahaman penggunaan excel hanya pernah menggunakannya saja, berikutnya setelah pelatihan dinyatakan selesai dilakukan lagi tes untuk mengetahui efektifitas pelaksanaan pelatihan dan hasilnya sesuai dengan materi yang disampaikan $100 \%$ peserta pelatihan dapat menerima materi pelatihan dan sangat memahaminya sehingga peserta mampu mengolah data nilai menggunakan excel dengan baik.
\end{abstract}

Kata kunci-Nilai, Siswa, LPPM, Excel, Materi, Peserta.

\section{PENDAHULUAN.}

Pengabdian kepada masyarakat (PkM) merupakan kewajiban yang harus dilaksanakan sesuai dengan amanat Tri Dharma Perguruan Tinggi, dilaksanakan setiap semester oleh civitas STTP, STTP Perguruan Tinggi berbasis teknologi informasi sehingga pengabdian yang dilakukannya mengarah pada teknologi sesuai dengan keahlian para dosen dan mahasiswanya, Perkembangan teknologi informasi dan komunikasi(TIK), dalam hal ini teknologi yang mendukung terlaksananya kegiatan (pendukung) pembelajaran saat ini sangat banyak dan menawarkan kemudahan serta kemudahan sesuai ke unggulannya masing-masing, salah satunya Ms. Excel yang bisa di manfaatkan sebagai sarana pembuatan aplikasi pengolahan data nilai.Media ini sangat banyak sekali digunakan di sebagai sarana pengolahan data yang sangat familiar.

Aplikasi Ms. Excel sebagai sarana pembuatan aplikasi pengolahan data nilai ini sangat di sarankan karena memiliki fitur dan menu yang sesuai dengan standar penulisan yang disarankan para ahli yang kompeten, sehingga pada saat penyusunan pada Ms. Excel ini pembuat aplikasi tinggal klik menu yang di maksud maka di dapat hasil tulisan (hitungan/pengolah data) yang baik (standar), selain itu Ms. Excel merupakan software pengolah data yang include dalam software pada sistem komputer dan biasanya benar-benar atau merupakan software asli yang di buat Microsoft sehingga tidak ditemui bagian menu yang rusak (crash), selain itu apa bila ingin mengupgrade, atau mengganti ke versi terbaru Microsoft menyediakan dengan mudah.

Pada pemaparan diatas dituntut agar para Guru Pelajaran Umum harus selalu meningkatkan kualitas pembelajaran dengan menggunakan semua resource terkait, sehingga dipandang perlu untuk diadakan pelatihan pembuatan aplikasi pengolahan data nilai ini, merupakan kelanjutan hasil 
kerja sama yang dilakukan oleh Sekolah Tinggi Teknologi Pagaralam dan Pihak SMAN 2 Kota Pagar Alam, yang mana kegiatan ini rutin dilakukan oleh pihak Sekolah Tinggi Teknologi Pagaralam (STTP).

\section{METODE.}

Metode pelaksanaan pengabdian kepada masyarakat $(\mathrm{PkM})$ ini dilakukan secara mandiri oleh dosen pengabdi, yang mana materi disampaikan dengan cara menyimak materi secara langsung yang disampaikan oleh narasumber, menjelaskan fitur, lalu praktek setelah para peserta memahami terhadap materi yang sudah disampaikan.

\subsection{Pengabdian Pada Masyarakat (PkM).}

Kegiatan pengabdian merupakan kegiatan bertujuan membantu pada ativitas tertentu tanpa mengharapkan balasan apa pun, yang mana program pengabdian ini dilaksanakan oleh elemen kampus perguruan tinggi (Universitas, Institut, Sekolah Tinggi, Akademi atau pun Politeknik), yang bertujuan untuk memberikan kontribusi yang nyata bagi kesejahteraan dan kemajuan bangsa Indonesia. Kegiatan pengabdian kepada masyarakat ini pada Perguruan Tinggi termasuk kedalam 3 landasan yang disebut Tri Dharma Perguruan Tinggi, yang bertujuan diantaranya sebagai berikut:

1. Meningkatkan daya inovasi teknologi untuk mendorong perkembangan ekonomi dengan melakukan komersialisasi hasil temuan penelitian.

2. Menyampaikan solusi kebaikan yang berasal dari kajian ilmiah atas kebutuhan, tantangan, atau permasalahan, secara langsung maupun tidak langsung.

3. Melaksanakan program yang mengentaskan masyarakat tersisih (preferential option for the poor) dalam seluruh strata, pada masyarakat yang tersisih secara ekonomi, politik, sosial maupun budaya.

4. Melaksanakan rekayasa dan alih teknologi, ilmu serta seni dalam masyarakat untuk kesejahteraan dan kelestarian kehidupan.

5. Selalu menumbuhkan jiwa dan karakter sosial yang menjadi panutan dan ide bagi masyarakat umum sehingga menumbuhkan jiwa dan semangat optimism yang tinggi.

\subsection{Nilai.}

Nilai adalah alat yang menunjukkan alasan dasar bahwa "cara pelaksanaan atau keadaan akhir tertentu lebih disukai secara sosial dibandingkan cara pelaksanaan atau keadaan akhir yang berlawanan. Nilai memuat elemen pertimbangan yang membawa ide-ide seorang individu mengenai hal-hal yang benar, baik, atau diinginkan (Wikipedia).

\subsection{Microsoft Excel.}

Microsoft excel merupakan aplikasi komputer pengolahan data yang kebanyakan berupa pengolaha perhitungan data berupa data angka, saat ini program Microsoft excel telah menyatu atau terbundel dalam Microsoft office bersama word, ppt dan lain-lain, berikut cara menjalankannya:

1. Dobel klik ikon MS EXCEL (jika ada) yang terdapat pada layar desktop komputer, atau

2. Klik ikon MS EXCEL pada MS Office Shortcut Bar (jika ada), atau

3. Melalui menu Start $\rightarrow$ Programs $\rightarrow$ Microsoft Excel, atau

4. Melalui menu Start $\rightarrow$ Run $\rightarrow$ Browse $\rightarrow$ (cari berkas Excel.exe).

\subsection{Pre \& Pos Tes.}

Pre Test yaitu suatu bentuk pertanyaan, yang dilontarkan guru kepada muridnya sebelum memulai suatu pelajaran. Pertanyaan yang ditanya adalah materi yang akan diajar pada hari itu (materi baru). Pertanyaan itu biasanya dilakukan guru di awal pembukaan pelajaran. Pre test diberikan dengan maksud untuk mengetahui apakah ada diantara murid yang sudah mengetahui mengenai materi yang akan diajarkan. Pre test juga bisa di artikan sebagai kegiatan menguji tingkatan pengetahuan siswa terhadap materi yang akan disampaikan, kegiatan pre test dilakukan sebelum kegiatan pengajaran diberikan. Adapun manfaat dari diadakannya pree test adalah untuk mengetahui kemampuan awal siswa mengenai pelajaran yang disampaikan. Dengan mengetahui 
kemampuan awal siswa ini, guru akan dapat menentukan cara penyampaian pelajaran yang akan di tempuhnya nanti.

Post test merupakan bentuk pertanyaan yang diberikan setelah pelajaran/materi telah disampaikan. Singkatnya, post test adalah evalausi akhir saat materi yang di ajarkan pada hari itu telah diberikan yang mana seorang guru memberikan post test dengan maksud apakah murid sudah mengerti dan memahami mengenai materi yang baru saja diberikan pada hari itu. Manfaat dari diadakannya post test ini adalah untuk memperoleh gambaran tentang kemampuan yang dicapai setelah berakhirnya penyampaian pelajaran. Hasil post test ini dibandingkan dengan hasil pree test yang telah dilakukan sehingga akan diketahui seberapa jauh efek atau pengaruh dari pengajaran yang telah dilakukan, disamping sekaligus dapat diketahui bagian bagian mana dari bahan pengajaran yang masih belum dipahami oleh sebagian besar siswa.

\subsection{Penyelesaian Masalah.}

Penyelesaian permasalahan kekurangan kemampuan pengolahan data nilai pada SMAN 2 Kota Pagar Alam dilakukan dengan melakukan kerja sama dengan civitas akademika STTP yang sedang melakukan pengabdian, dan mengadakan pelatihan pengolahan data nilai yang dilangsungkan selama satu hari di SMAN 2 Kota Pagar Alam yang mana narasumber adalah dosen STTP yang dibantu oleh beberapa orang Mahasiswa/Mahasiswi STTP, dilakukan dengan praktek secara langung, artinya pengolahan nilai secara langsung.

\section{PEMBAHASAN DAN HASIL.}

3.1. Realisasi \& Pemecahan Masalah.

Realisasi pelaksanaan kegiatan pengabdian kepada masyarakat $(\mathrm{PkM})$ dilakukan secara terinci dan termanajemen agar pelaksanaan kegiatan $\mathrm{PkM}$ berjalan dengan baik dan materi pelatihan tersampaikan dan peserta pelatihan memiliki pemahaman sesuai dengan harapan dan bisa melakukan pengolahan data nilai menggunakan excel dengan baik dan benar (akurat), maka berikut rincian kegiatan yang dilakukan:

Tabel 1. Kegiatan

\begin{tabular}{|l|l|c|}
\hline \multicolumn{1}{|c|}{ Waktu } & \multicolumn{1}{|c|}{ Materi } & \multirow{2}{|c|}{ Penyaji } \\
\hline $08.00-09.00$ & Pre Test & \multirow{3}{*}{ Desi Puspita, M.Kom } \\
$09.00-09.30$ & Persiapan Membuat Aplikasi pengolah data nilai & \\
\hline $09.30-12.00$ & Panduan Membuat aplikasidan Tutorial Membuat & \\
& aplikasi pengolah data nilai dengan Ms. Excel & \\
$12.00-12.30$ & Ishoma & \\
$12.30-13.00$ & Post-test & \\
\hline
\end{tabular}

Tabel 1. Diatas menjelaskan tentang rincian kegiatan yang dilakukan pada saat pengolahan data nilai menggunakan Microsoft excel pada SMAN 2 Kota Pagar Alam. Kegiatan pengabdian dilakukan diawali dengan pre tes, pre tes dilakukan pada awal kegiatan pengabdian, pre tes bertujuan untuk memahami kemampuan peserta pelatihan sebelum diadakan pelatihan agar narasumber mengetahui tingkat pemahaman peserta sehingga narasumber melakukan pengabdian lebih efektif karena memberikan materi sesuai dengan kebutuhan dari peserta yang ada.

Setelah dilakukan pre tes, berikutnya disampaikan teori tentang teknologi informasi yaitu aplikasi Microsoft excel dan persiapan pengolahan data menggunakan excel, setelah dirasa cukup mengenalkan aplikasi, tools dan fitur excel kepada peserta selanjutnya, seluruh peserta mempraktekan apa-apa yang disampaikan secara teori yang didampingi oleh narasumber dan bantuan beberapa mahasiswa yang mendampingi, selanjutnya dilakukan pengolahan nilai menggunakan excel agar peserta terbiasa dengan excel sehingga peserta dipersilahkan untuk langsung mengolah nilai dengan excel, dan dapat bertanya kepada narasumber apa bila ditemukan permasalahan pada saat pengolahan data nilai tadi, terakhir setelah semua sesuai rincian dilaksanakan adalah dilakukan tes lagi, tes terakhir untuk mengetahui keberhasilan dari pelaksanaan pengabdian yang dilakukan, tes dilakukan terhadap seluruh peserta pelatihan dan hasilnya sangat menggembirakan karena seluruh peserta mampu memahami dengan baik materi 
yang disampaikan narasumber. Bahkan mereka mengusulkan pelatihan dengan materi yang berbeda dilakukan secara rutin.

\subsection{Pembahasan \& Hasil.}

Maka berdasarkan kegiatan yang dilakukan point 3.1 diatas berikut ini merupakan pembahasan dan hasilnya dari pengbdian kepada masyarakat dengan tema pelatihan pengolahan data nilai menggunakan excel di SMAN 2 Kota Pagar Alam. Berdasarkan poin 3.1 diatas kegiatan pengabdian yang dilakukan dimulai dengan pre tes terhadap seluruh peserta yang mengikuti pelatihan dimana tujuannya untuk mengetahui kemampuan peserta terhadap excel, sehingga pelatihan menjadi lebih efisien dan mengena sesuai dengan kebutuhan peserta. Dari hasil pre tes ini diketahui hanya $2 \%$ peserta yang mengenal excel cukup baik tetapi tidak diaplikasikan untuk mengolah data nilai, sisanya hanya sekedar memahami ada excel tetapi belum menggunakannya, sehingga disimpulkan pelatihan sangat diperlukan.

Berikutnya setelah tes disampaikan materi pelatihan secara teori dan contoh-contoh serta cara penulisan perintah, rumus-rumus perintah dan logika perhitungan yang ada dalam excel sampai peserta memahami logika tersebut, berikutnya setelah logika dan rumus-rumus di pahami peserta diminta untuk mempraktekan secara langsung dengan melakukan pengolahan data nilai yang dibawa untuk dimasukan kedalam excel untuk dilakukan perhitungan dengan bimbingan narasumber, apa bila ada kesalahan peserta bisa langsung bertanya kepada narasumber, sehingga berikut merupakan rincian keberhasilan dari pelatihan yang dilakukan dideskripsikan tabel 2 dibawah ini:

Tabel 2. Keberhasilan Pelaksanaan Kegiatan

\begin{tabular}{|c|l|l|}
\hline Pertemuan & \multicolumn{1}{|c|}{ Materi } & \multicolumn{1}{|c|}{ Hasil } \\
\hline 1 & Persiapan & $\begin{array}{l}\text { Mampu menganalisis data dan mengumpulkan } \\
\text { data untuk diolah menggunakan excel }\end{array}$ \\
\hline 2 & $\begin{array}{l}\text { Pengenalan fitur dan tools yang } \\
\text { ada pada excel }\end{array}$ & $\begin{array}{l}\text { Peserta mampu memahami dan mengetahui } \\
\text { tools dan fitur yang ada pada excel, logika } \\
\text { perintah dan perhitungan logis pada excel. }\end{array}$ \\
\hline 3 & $\begin{array}{l}\text { Menunjukan contoh mengolah } \\
\text { data nilai }\end{array}$ & $\begin{array}{l}\text { Peserta mengetahui dan memanfaatkan tools } \\
\text { aplikasi excel dengan baik dengan melihat } \\
\text { contoh. }\end{array}$ \\
\hline 4 & Membuat latihan dengan excel & $\begin{array}{l}\text { Peserta pelatihan mampu mengolah data nilai } \\
\text { dengan excel. }\end{array}$ \\
\hline
\end{tabular}

Setelah pelatihan pengolahan data nilai menggunakan Microsoft excel dilakukan dan berdasarkan tabel 2 diatas berhasil dengan sangat baik maka berikutnya dilakukan tes lagi (Pos tes), yang tujuannya untuk mengetahui keberhasilan dari pelatihan yang dilakukan sehingga bisa ada input bagi perbaikan pelaksanaan pelatihan dan pengabdian yang diadakan lain waktu, dari hasil pos tes diketahui bahwa peserta 100\% mampu menjalankan dan mengolah data nilai menggunakan aplikasi excel dengan sangat baik, sehingga data nilai menjadi lebih bisa dipercaya karena data yang dihasilkan dengan metode dan cara yang sangat akurat, sehingga diyakini memiliki rasa keadilan yang tinggi karena data nilai pasti benar dan tidak ada yang dirugikan karena kesalahan hitung nilai, sehingga bisa diidentifikasi berikut merupakan hasil akhirnya, yaitu:
a. Para peserta pelatihan guru SMAN 2 Pagaralam mempunyai pengetahuan dan pemahaman yang baik tentang pengolahan nilai menggunakan excel.
b. Seluruh peserta guru SMAN 2 Pagaralam menjadi sangat paham terhadap teknologi informasi yang lebih aplikatif untuk mendukung dalam pengolahan data yang diperlukannya.
c. Para guru SMAN 2 Pagaralam sudah terbantu dalam pemberian pemahaman terhadap teknologi informasi up to date yang aplikatif.
d. Dengan perhitungan yang akurat benar tidak ada yang dirugikan karena kesalahan hitung dari data nilai yang ada.
e. Membantu pimpinan SMAN 2 dalam meningkatkan nilai lebih pada pegawai SMAN 2 Kota Pagar Alam.




\section{KESIMPULAN}

Pada pelaksanaan pengabdian masyarakat ini yang dilakukan di SMAN 2 Pagaralam dengan tujuan melatih Guru dalam melakukan pengolahan terhadap data nilai didapatkan kesimpulan sebagai berikut:

a. Melakukan proses pembelajaran dengan cara belajar aplikasi secara langsung ternyata sudah mampu meningkatkan semangat belajar menjadi lebih baik (giat).

b. Menambah softskills para Guru SMA 2 Pagaralam

c. Meningkatkan rasa percaya diri dengan kemampuan.

d. Membantu guru pelajaran TIK dalam hal memahamkan guru lain terhadap suatu aplikasi tertentu.

\section{SARAN}

Maka berdasarkan pengalaman yang dilihat dan dirasakan penulis saat melakukan pengabdian ini maka, penulis dalam hal ini bisa memberikan saran:

a. Waktu pengabdian dilakukan lebih lama

b. Materi ditambah/ lebih kompleks dan lebih banyak contoh.

\section{UCAPAN TERIMA KASIH}

Penulis mengucapkan terima kasih kepada Panitia KKN dan Pengabdian bagi Dosen, terima kasih kepada keluarga, kawan-kawan dosen.

\section{DAFTAR PUSTAKA}

[1] Indonesia Services Education HP Tim, 2001, Manajemen Sistem Belajar Di Dunia Maya, Majalah Info Komputer.

[2] Muslim, B. 2018. Pelatihan aplikasi editing video dengan filmora., Laporan Pengabdian Kepada Masyarakat, LPPM STT Pagaralam.

[3] Muslim, B. 2018. Pelatihan Pembuatan Blog Bagi Guru Ma Ponpes Darul Mutaqin Kota Pagaralam. NGABDIMAS. Vol 1. No.1. Bulan Juni, Hal. 6-11.

[4] M.H Jogiyanto, 1995, Pengenalan Komputer, Andi Offset Yogyakarta.

[5] B. Muslim, Pengantar teknologi informasi. Yogyakarta: Deepublish, 2017.

[6] Muslim, B. (2018). Analisis system informasi (SI) terintegrasi di Perguruan Tinggi (PT) (Studi Kasus: STT Pagaralam). Jurnal Teknologi Informasi MURA, Vol 10. Page 83-91.

[7] Muslim, B (2014). Analisis rencana aplikasi teknologi informasi pada STT Pagar Alam. Proseding semnastik dan Magma. Issue: Aplikasi Teknologi dan sistem Informasi. PPP UBD Pres. Pages 397-404.

[8] Hutchinson E. Sarah and Sawyer C. Stacey, 2000, Computers, Communications \& Information, McGraw Hill Companies Inc.

[9] Horsley, M., Knight, B., \& Huntly, H. 2010. The role of textbooks and other teaching and learning resources in higher education in Australia: Change and continuity in supporting learning. IARTEM 1-Journal. 3(2). 43-61.

[10] Sadiman, A.S., Rahardjo, R., Haryono, A., \& Rahardjito. 2006. Media pendidikan: Pengertian, pengembangan, dan pemanfaatan. Jakarta: Rajagrafindo Persada.

[11] Menristekdikti. 2016. Panduan Pelaksanaan Penelitian dan Pengabdian Masyarakat di Perguruan Tinggi Edisi X Tahun 2016. hlm 4.

[12] Nilai. https://id.wikipedia.org/wiki/Nilai, 10-09-2020

[13] Isro'Mukti, Y. (2017). Sistem Informasi Madrasah Aliyah Negeri Pagar Alam Berbasis Web. Indonesian Journal of Computer Science, 6(2), 192-205. 
[14] Mukti, Y. (2017). Perencanaan Strategis Sistem Informasi Dan Teknologi Informasi Pada Sekolah Menengah Kejuruan Negeri 2 Pagar Alam. JURNAL ILMIAH BETRIK: Besemah Teknologi Informasi dan Komputer, 8(02), 83-92.

[15] Arif, A., \& Mukti, Y. (2017). Rancang Bangun Website Sekolah Menengah Pertama (SMP) Negeri 8 Kota Pagar Alam. JURNAL ILMIAH BETRIK: Besemah Teknologi Informasi dan Komputer, 8(03), 156-165.

[16] Isro'Mukti, Y. (2018, October). Sistem Informasi Manajemen Aset Sekolah Tinggi Teknologi Pagaralam Berbasis Web. In Seminar Nasional Teknologi Informasi dan Komunikasi (SEMNASTIK) (Vol. 1, No. 1, pp. 632-638).

[17] Mukti, Y. (2018). Rancang Bangun Website Sekolah Dengan Metode User Centered Design (UCD). JURNAL ILMIAH BETRIK: Besemah Teknologi Informasi dan Komputer, 9(02), 84-95.

[18] Mukti, Y. (2018). Pelatihan Maintance Komputer SMAN Pagar Gunung. NGABDIMAS, $1(1), 47-51$. 